NASA Technical Memorandum 100825

\title{
High Frequency Ultrasonic Characterization of Sintered SiC
}

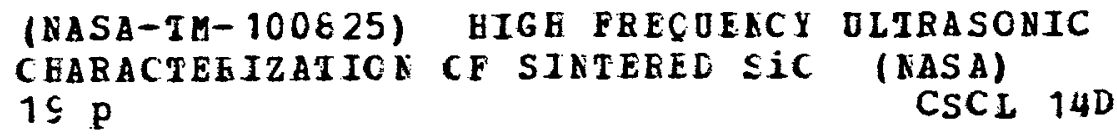

George Y. Baaklini, Edward R. Generazio, and James D. Kiser Lewis Research Center

Cleveland, Ohio

Prepared for the 11th Annual Conference on Composite and Advanced Ceramic Materials sponsored by the American Ceramic Society Cocoa Beach, Florida, January 18-23, 1987 
HIGH FREQUENCY ULTRASONIC CHARACTERIZATION OF SINTERED SIC

George Y. Baaklini, Edward R: Generazio, and James D. Kiser National Aeronautics and Space Administration

Lewis Research Center

Cleveland, Ohio 44135

\section{ABSTRACT}

High frequency $60-$ to $160-\mathrm{MHz}$ ultrasonic nondestructive evaluation was used to characterize variations in density and microstructural constituents of sintered SiC bars. Ultrasonic characterization methods included longitudinal velocity, reflection coefficient, and precise attenuation measurements. The Sic bars were tailored to provide bulk densities ranging from 90 to 98 percent of theoretical, average grain sizes ranging from 3.0 to $12.0 \mu \mathrm{m}$, and average pore sizes ranging from 1.5 to $4.0 \mu \mathrm{m}$. Velocity correlated with specimen bulk density irrespective of specimen average grain size, average pore size, and average pore orientation. Attenuation coefficient was found to be sensitive to both density and average pore size variations, but was not affected by large differences in average grain size.

\section{INTRODUCTION}

Reliable quantitative ceramic characterization via nondestructive evaluation (NDE) methodologies is being aggressively pursued throughout the ceramic and nondestructive testing communities. It is necessary to develop NDE techniques for characterizing microstructural and morphological factors which ultimately govern the strength, toughness, and dynamic performance of ceramics. 1 This is because reliability assurance of ceramics depends not only on defect detection but also on mechanical strength verification and associated properties which are sensitive to microstructural characteristics. The ability to nondestructively probe the microstructure of a ceramic via ultrasonic 
velocity and attenuation is of high interest for in situ monitoring and control of material processing, and for material properties verification of finished products. Hence, pulse-echo ultrasonics, an effective technique for the characterization of the microstructure and density of structural ceramics, 2-6 was chosen for interrogating the sintered SiC system.

Silicon carbides have fine microstructural constituents, ${ }^{7-10}$ that is, grains and pores range in size from 1 to $10 \mu \mathrm{m}$. High frequency (short wavelength) ultrasound is required for the characterization of these fine ceramics. But high frequency ultrasonic measurements using contact pulse-echo techniques are limited by variations in specimen surface roughness and couplant thickness. 3 In addition, polished ceramic surfaces are costly and impractical. Consequently, there exists a need (1) to determine an acceptable surface roughness for the silicon carbide system where reliable attenuation measurements can be obtained, (2) to define the proper frequency regime for microstructural characterization, and ( 3 ) to quantitatively correlate precision ultrasonic measurements with material properties to the extent that they are controlled by microstructural characteristics.

This work will identify an acceptable specimen surface roughness for obtaining reliable high frequency, contact-pulse-echo ultrasonic attenuation measurements. Further, it will quantitatively assess the dependence of ultrasonic attenuation and velocity on the microstructure and density of sintered silicon carbide.

\section{EXPERIMENTAL}

\section{Sample Preparation}

Green test bars were formed by dry pressing -100 mesh $\alpha-S i C$ powder that contained boron and carbonaceous resin binders in a double-action 
tungsten-lined die at a pressure of $120 \mathrm{MPa}$. These bars were then vacuum sealed in thin-wall latex tubing and cold isopressed at $414 \mathrm{MPa}$. The green bars were sintered in batches under $0.1 \mathrm{MPa}$ argon pressure at different temperatures for different sintering hold times (Table I)." Some'sintered specimens were further hot isostatically pressed under $138 \mathrm{MPa}$ argon pressure at various temperatures for different hold times (Table I). These different. sintering and hot isostatic pressing conditions were employed in order to "tailor" the densities and microstructures of the different batches. These conditions provided batches with bulk densities ranging from 2.92 to $3.13 \mathrm{~g} / \mathrm{cm}^{3}$, with average grain sizes ranging from 3.36 to $11.56 \mu \mathrm{m}$, and with average pore sizes ranging from 1.60 to $3.82 \mu \mathrm{m}$. Täble II lists mean pore sizes, mean grain sizes, and their corresponding shapes for all eight batches. All bars were machined, with the four long edges beveled. These specimens were further polished to $0.45,0.36,0.11$, and $0.07 \mu \mathrm{m} r \mathrm{~ms}$ surface finishes. Nominal test bar dimensions were 0.27 by 0.56 by $3.17 \mathrm{~cm}$.

\section{Microstructural Characterization}

Mean pore size, shape, and orientation were determined from photomicrographs of a polished representative sample from each batch by applying two-dimensional Fourier transform theory. 11 Briefly, nine different microstructural images from different areas on the same sample were digitally recorded into a 512 by 512 pixel array via a vidicon camera connected to a video digitizer. The pore boundaries were enhanced by two dimensional digital gradient 12 of the image. All pixels between pores were set to a zero value while pixels belonging to pores were set to a constant nonzero value. Next, a tone-pulse-encoded image containing the fundamental harmonics of each pore was generated in all directions $(0$ to $2 \pi \mathrm{rad}$ ). The tone pulse had a width equal 
to the width of the pore. Tone-pulse-encoded images were digitally Fourier transformed by using a complex 512 point, hardwired, fast Fourier transform array processor. This enabled the determination of the density of frequency components, from which the density of length components were determined. The latter corresponds directly to the two-dimensional pore size distribution. function from which the mean pore size, shape, and orientation are obtained.11 Figure 1 shows the pore size distribution function (Fig. 1(a)), the mean pore size, shape, and orientation (Fig. I(b)), and the polished microstructure (Fig. 1(c)) for batch 2 .

Mean grain size was determined from photomicrographs of a polished and etched representative sample of each batch by using an interactive image analysis computer system. The computer system is designed for data acquisition and computation of geometric characteristics. By tracing grain boundaries on a digitizing tablet, grain sizes were measured and mean grain sizes were determined for all batches.

\section{Ultrasonic Evaluation}

Figure 2 shows a typical configuration of the pulse-echo technique which was used for the ultrasonic measurements. Reproducible velocity and attenuation measurements were performed on all samples, through the thickness of each specimen at different locations. The pulse-echo technique, with a $100 \mathrm{MHz}$ broadband longitudinal-wave transducer, was used to measure the cross correlation velocity 13 and the attenuation coefficient ${ }^{3}$ from the first and second back surface reflections. The frequency dependent reflection coefficient was incorporated for precision.attenuation measurements. A valid frequency zone was defined between 60 and $160 \mathrm{MHz}$ outside of which the reflection coefficient is subject to large errors. 
The reflection coefficient of the buffer rod-couplant-sample (BCS) interface as a function of frequency, $f$, for a specific surface roughness can be determined from the ratio of the magnitude of the Fourier spectra of the front surface reflection with the sample present on the buffer $\operatorname{rod},\left|F S_{2}(f)\right|$, to that of the front surface reflection without the sample present on the buffer $\operatorname{rod},\left|F S_{\rceil}(f)\right|$

$$
|R(f)|=\frac{\left|F S_{2}(f)\right|}{\left|F S_{1}(f)\right|}
$$

The frequency dependent attenuation coefficient can be determined from the Fourier magnitudes of the first and second back-surface reflections, $\left|B_{j}(f)\right|$ and $\left|B_{2}(f)\right|$, respectively and is given by 3

$$
\alpha(f)=\frac{1}{2 \Delta X} \ln \left\{\frac{\left|B_{1}(f)\right||R(f)|}{\left|B_{2}(f)\right|}\right\}
$$

where $\Delta X$ is the thickness of the sample.

\section{RESULTS AND DISCUSSION}

Reflection Coefficient and Surface Roughness

The experimentally determined reflection coefficients as a function of frequency for machined and polished specimens were obtained by using Eq. (1). Figure 3 shows experimental reflection coefficients for a typical SiC sample at varying surface roughness. A decrease in the surface roughness leads to a decrease in the couplant thickness. This results in a decrease in the reflection coefficient to approach the theoretical value of the zero frequency reflection coefficient $|R(0)|$ given by

$$
|R(0)|=\left|\frac{z_{3}-z_{1}}{z_{3}+z_{1}}\right|
$$


where $z_{1}$ and $z_{3}$ are the acoustical impedance of the buffer rod and sample, respectively.

Figure 4 shows that the reflection coefficient is an increasing function of the maximum peak-to-valley roughness $R_{t}$ at a fixed frequency. It also shows that samples with different densities may yield similar reflection coefficient values for different maximum peak-to-valley roughnesses. This difference in roughness will change the effective couplant thickness and the contact area between the sample and the buffer rod surface. In addition, it may include other topological variations, related to that specific batch or sample, which scatter energy out of the main pulse in a random manner. Polishing sintered silicon carbide samples down to a surface roughness of $0.11 \mu \mathrm{m} \mathrm{rms}$ is necessary to approach the theoretical zero frequency reflection coefficients for the batches used here. However, it is still necessary to incorporate the frequency dependent reflection coefficient in the ultrasonic attenuation measurements in order to improve the accuracy of these measurements. 3

Attenuation Coefficient and Microstructural Variations

The attenuation coefficient as a function of frequency for each sample was obtained by using Eq. (2) where the frequency dependent reflection coefficient was incorporated. Figure 5 shows the attenuation coefficient measurements for varying surface roughness of the same sample that was considered in Fig. 3. It is noted that for surface roughness less than or equal to $0.11 \mu \mathrm{m}$ rms attenuation measurements ( $F i g .5$ ) become less dependent on the surface roughness in the frequency regime shown. In addition, Fig. 6 
shows the actual percent uncertainty of the measured attenuation coefficient. due to the uncertainty in the pulse amplitudes. The actual percent uncertainty was calculated by using Eq. (4) below ${ }^{3}$

$\left|\frac{\sigma_{\alpha}}{\alpha}\right|(100)=\frac{1}{2 \alpha \Delta X}\left(\frac{100}{(s / n)}\right)\left[\left(\frac{\left(\exp (2 \alpha \Delta X)+|R|^{2}\right) \exp (2 \alpha \Delta X)}{\left(1-|R|^{2}\right)^{2}}+1\right) \frac{1}{|R|^{2}}+1\right]^{1 / 2}(4)$ where $\sigma_{\alpha}$ is the variance of the attenuation, and $s / n$ is the signal-to-noise ratio of the main pulse $F S_{l}(f)$. For varying surface roughness the percent uncertainty is less than 5 percent, except when the attenuation approaches zero, here the percent uncertainty increases dramatically. Hence polishing sintered silicon carbide samples down to a surface roughness of less than or equal to $0.11 \mu \mathrm{m} r m s$ is necessary to obtain accurate comparative attenuation measurements for samples from different batches.

Attenuation coefficient results are plotted as a function of frequency for all batches in Fig. 7. Solid lines represent the upper and lower boundaries of the data for each batch $(1,4$, and 5HP) of specimens. The data for batches 2, 2HP, 3, 3HP, and 4HP were spread and overlapped between the two solid lines as indicated by the arrows in Fig. 7 , making it difficult to clearly show all the data separately for each batch. At $100 \mathrm{MHz}$ the attenuation coefficient does differentiate substantialiy. between batches, on the basis of their density and microstructural constituents. The attenuation and microstructural data for batches 1,4 , and $5 \mathrm{HP}$ does not show clear evidence of the attenuation dependence on one single scattering mechanism. But from attenuation data 14 measured on the same silicon carbide system, jt was found that attenuation was not due to grain boundary scattering. Hence, 
pore site scattering is the dominant attenuation mechanism. Attenuation due to pore site scattering depends mainly on the average pore size and the porosity distribution (density).

Attenuation dependency on average pore size can be seen by comparing batch 1 and batch 4HP (with a similar density) attenuation coefficient data shown in Fig. 8. For an average pore size increase of $\sim 115$ percent the mean attenuation coefficient increased by 300 percent at $100 \mathrm{MHz}$.

Attenuation dependency on density can be demonstrated by comparing batch 4 and batch 4HP attenuation coefficient data shown in Fig. 8. An $\sim 1.97$ percent increase in density reflects a 150 percent decrease in mean attenuation coefficient at $100 \mathrm{MHz}$.

$$
\text { Velocity and Density }
$$

The average ultrasonic velocity through the SiC bars was plotted as a function of specimen bulk density in Fig. $9(2)$. The average velocity for each of batch 1,2, $2 \mathrm{HP}, 3,3 \mathrm{HP}, 4,4 \mathrm{HP}$, and $5 \mathrm{HP}$ are $1.181,1.175,1.186,1.186$, $1.176,1.190,1.160,1.188$, and $1.101 \mathrm{~cm} / \mu \mathrm{sec}$, respectively. The data show that velocity is an increasing function of bulk density. This result agrees with previous findings. 5-6

Figure $g(b)$ shows the velocity data for batches $1,4,4 H P$, and $5 H P$. Velocity was not as sensitive to changes in mean grain and pore size as it was to changes in bulk density, that is, no substantial difference in velocity was detected between batch 4HP $(1.188 \mathrm{~cm} / \mu \mathrm{s})$ and batch $1(1.181 \mathrm{~cm} / \mu \mathrm{s})$, each of which had average densities of $3.11 \mathrm{~g} / \mathrm{cm}^{3}$, even though $4 \mathrm{HP}$ had more than twice the mean grain and pore size of batch 1 :

Velocity was not sensitive to preferred mean pore orientation for batches with identical densities and with roughly close average pore and grain sizes 
(Fig. $9(\mathrm{C})$ ). In the case of batch 2 the major axis of the mean pore (Fig. 1) was perpendicular to the sound propagation direction, whereas the mean pore in batch 3 had its major axis paraliel to the sound of propagation.

\section{GENERAL DISCUSSION}

Attenuation measurement, although sensitive to the surface roughness of silicon carbide ceramics, is an excellent indicator of porosity variations between specimens. Further, for a polished system (surface roughness less than or equal to $0.11 \mu \mathrm{m}$ rms) where porosity is the main ultrasonic scattering mechanism (assuming similar average pore size), attenuation measurement is a more sensitive indicator than velocity measurement in detecting and monitoring density differences. For example, by comparing the data for batch 4 and $4 \mathrm{HP}$, a 1.97 percent increase in density was characterized by a 150 percent decrease in mean attenuation coefficient at $100 \mathrm{MHz}$ as opposed to a 1.7 percent increase in average velocity.

Velocity measurement, which is less sensitive to microstructural variations, is an attractive indicator of density variations in machined or polished ceramics. Especially, when both density and mean pore size are changing at the same time (general case).

For ceramic batches with very fine microstructural constituents and near full theoretical density (similar to or of better quality than batch 1), higher frequency regimes (up to $300 \mathrm{MHz}$ ) need to be considered for attenuation measurements to detect porosity variations between specimens and or batches. Such fine hot isostatically pressed SiC has recently been developed. 15 In addition, sintered silicon nitride materials in general have microstructures that are up to one order of magnitude finer 16 than silicon carbides. 


\section{CONCLUSIONS}

Surface roughness constraints on comparative and precise attenuation measurements have been identified for the sintered SiC system. A surface roughness of $0.11 \mu \mathrm{m} r \mathrm{~ms}$ is required for accurate ultrasonic attenuation measurements. Ultrasonic longitudinal velocity correlated well with specimen bulk densities. Velocity was not found to be sensitive to average grain size, average pore size, and average pore orientation. Velocity measurement is an attractive ultrasonic parameter for monitoring and evaluating the density of machined or polished ceramics. Precise attenuation measurements, which are sensitive to variations in surface roughness, were obtained by incorporating the frequency dependent reflection coefficient in the signal analysis. These measurements are found to be extremely sensitive to density and average pore size. When porosity is the only scattering mechanism that affects attenuation measurements, the latter is expected to present a much higher sensitivity than velocity measurements in detecting minute density variations. 


\section{REFERENCES}

lVary, A., "Quantitative Ultrasonic Evaluation of Engineering Properties in Metals, Composites, and Ceramics"; NASA TM-81530, June 1980.

2Evans, A.G., et al, "Ultrasonic Attenuation. in Ceramics," J. Appl.Phys.

49 [5], pp. 2669-2679 May 1978.

3Generazio, E.R., "The Role of the Reflection Coefficient in Precision Measurement of Ultrasonic Attenuation," Mater. Eval. 43 [8], 995-1004 (1985).

4Kupperman, D.S., "Application of NDE Methods to Green Ceramics: Initial Results, ". ANL/FE-83-25, March 1984.

5S.J.Klima, and G.Y.Baaklini, "Nondestructive Characterization of Structural Ceramics," SAMPE Q. 17 [3], April (1986).

6Thorp, J.S., and Bushell, T.G., "Ultrasonic Examination of Reaction Bonded Silicon Nitride;" J. Mater. Sci. 20, 2265-2274, 1985.

7Dutta, 5., "Sinterability. Strength and Oxidation of Alpha Silicon Carbide Powders," Journal of Materials Science 19, 1307-1313, 1984.

${ }^{8}$ Dutta, S., "Strength Optimization of a-SiC by Improved Processing, "NASA CP 2427, pp. 89-98, May 1986. 
9Hurst, J.B., and Millard, M.L., "Evaluation of a-SiC Sintering Using

Statistical Methods," J: Am: Ceram: Soc. 68 [7] C-1782181; July 1985.

10Helms, H.E., et al, "Ceramic Materials Development," pp. 49-63 in Ceramic Applications in Turbine Engines, Noyes Publications, Park Ridge, NJ, 1986.

${ }^{11}$ Generazio, E.R., "Determination of Grain Size Distribution Function Using Two-Dimensional Fourier Transforms of Tone Pulse Encoded Imáges, "Mater.

Evà̀l., $46[4] \cdot 528-534$ (1988).

12Gonzalez, R.C., and Wintż, P., Digital Image Processing, 1977, Addison-Wesley, Reading, MA, 1977.

13Hull, D.R., Kautz, H.E., and Vary, A., "Measurement of Ultrasonic Velocity :Using Phase-Slope and Cross Correlation Methods," Mater. Eval., 43 [11] $1455-1460(1985)$

14Generazio, E.R., Roth, D.J., and Baaklini, G.Y., "Imaging Subtle Microstructural Variations in Ceramics with Precision Ultrasonic Velocity and Attenuation Measurements," NASA TM-100129, November 1987.

150utta, S., "Improved Processing of a-SiC", Adv. Ceram. Mater., 1988. 
165anders, W.A., and Baaklini, G.Y., "Correlation of Processing and Sintering Variables with the Strength and Radiography of Silicon Nitride," Adv. Ceram. Mater. 3 [1] 88-94 1988.

TABLE I. - SINTERING AND HOT ISOSTATIC PRESSING CONDITIONS

\begin{tabular}{|c|c|c|c|c|c|c|c|c|}
\hline \multirow{2}{*}{$\begin{array}{l}\text { Batch } \\
\text { number }\end{array}$} & \multirow{2}{*}{$\begin{array}{l}\text { Number } \\
\text { of } \\
\text { specimen }\end{array}$} & \multicolumn{3}{|c|}{ Sintering } & \multicolumn{3}{|c|}{ Hot isostatic pressing } & \multirow{2}{*}{$\begin{array}{l}\text { Density, } \\
\mathrm{g} / \mathrm{cm}^{3} \\
\pm 0.01 \mathrm{~g} / \mathrm{cm}^{3}\end{array}$} \\
\hline & & $\begin{array}{l}\text { Temper- } \\
\text { ature, } \\
{ }^{\circ} \mathrm{C} \text {, }\end{array}$ & $\begin{array}{l}\text { Time, } \\
\text { hr }\end{array}$ & $\begin{array}{c}\text { Argon } \\
\text { pres- } \\
\text { sure, } \\
\text { MPa }\end{array}$ & $\begin{array}{l}\text { Temper- } \\
\text { ature, } \\
{ }^{\circ} \mathrm{C}\end{array}$ & $\underset{\mathrm{hr}}{\text { Time, }}$ & $\begin{array}{c}\text { Argon } \\
\text { pres- } \\
\text { sure, } \\
\mathrm{MPa}\end{array}$ & \\
\hline $\begin{array}{l}1 \\
2 \\
2 \mathrm{HP} \\
3 \\
3 \mathrm{HP} \\
4 \\
4 \mathrm{HP} \\
5 \mathrm{HP}\end{array}$ & $\begin{array}{r}10 \\
10 \\
7 \\
9 \\
9 \\
8 \\
8 \\
9\end{array}$ & $\begin{array}{l}2200 \\
2200 \\
2200 \\
2150 \\
2150 \\
2300 \\
2300 \\
2100\end{array}$ & $\begin{array}{l}0.5 \\
1.5 \\
1.5 \\
4.0 \\
4.0 \\
1.0 \\
1.0 \\
.75\end{array}$ & 0.1 & $\begin{array}{l}---- \\
-- \\
2100 \\
\overline{2100} \\
---- \\
2150 \\
2100\end{array}$ & $\begin{array}{l}--- \\
0.5 \\
0.5 \\
1.0 \\
1.0\end{array}$ & $\begin{array}{l}--- \\
--- \\
138 \\
138 \\
--- \\
138 \\
138\end{array}$ & $\begin{array}{l}3.11 \\
3.09 \\
3.13 \\
3.09 \\
3.12 \\
3.05 \\
3.11 \\
2.92\end{array}$ \\
\hline
\end{tabular}

TABLE II. - CHARACTERIZATION OF MICROSTRUCTURE

\begin{tabular}{|c|c|c|c|c|c|c|c|c|c|}
\hline \multirow{3}{*}{$\begin{array}{l}\text { Batch } \\
\text { number }\end{array}$} & \multirow{3}{*}{$\begin{array}{l}\text { Densitfy, } \\
\mathrm{g} / \mathrm{cm}^{3}\end{array}$} & \multicolumn{3}{|c|}{ Mean grain size, ${ }^{\mathrm{a}} \mu \mathrm{m}$} & \multirow[t]{3}{*}{ Grain shape } & \multicolumn{3}{|c|}{ Mean pore size, ${ }^{a} \mu \mathrm{m}$} & \multirow{3}{*}{$\begin{array}{c}\text { Pore } \\
\text { orientation }\end{array}$} \\
\hline & & \multirow{2}{*}{$\frac{\text { Circle }}{\text { Diameter }}$} & \multicolumn{2}{|c|}{ El1ipsec } & & \multirow{2}{*}{$\begin{array}{l}\text { Circle }^{d} \\
\text { Diameter }\end{array}$} & \multicolumn{2}{|c|}{ Ellipse ${ }^{a, e}$} & \\
\hline & & & Major & Minor & & & Major & Minor & \\
\hline 1 & 3.11 & 5.76 & 7.94 & 4.56 & Equiaxed and & 1.60 & 1.61 & 1.59 & --- \\
\hline 2 & 3.09 & 5.38 & 7.52 & 4.20 & Equiaxed and & 1.61 & 1.90 & 1.31 & Preferred \\
\hline $2 \mathrm{HP}$ & 3.13 & 6.75 & 9.61 & 5.15 & $\begin{array}{l}\text { Equiaxed and } \\
\text { elongated }\end{array}$ & 1.63 & 1.75 & 1.50 & \\
\hline 3 & 3.09 & 4.13 & 5.39 & 3.38 & $\begin{array}{l}\text { Equiaxed and } \\
\text { elongated }\end{array}$ & 1.82 & 2.04 & 1.59 & Preferred \\
\hline $3 \mathrm{HP}$ & 3.12 & 4.04 & 5.24 & 3.36 & $\begin{array}{l}\text { Equiaxed but } \\
\text { few elongated }\end{array}$ & 1.68 & 1.75 & 1.61 & \\
\hline $\begin{array}{l}4 \\
4 \mathrm{HP}\end{array}$ & $\begin{array}{l}3.05 \\
3.11\end{array}$ & $\begin{array}{l}11.56 \\
11.18 \\
3.36\end{array}$ & $\begin{array}{r}19.39 \\
18.08\end{array}$ & $\begin{array}{l}7.73 \\
7.82 \\
2.78\end{array}$ & Elongated & $\begin{array}{l}3.82 \\
3.44\end{array}$ & $\begin{array}{l}4.00 \\
3.60\end{array}$ & $\begin{array}{l}3.64 \\
3.27\end{array}$ & ------- \\
\hline
\end{tabular}

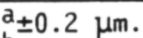

bssuming all grains are equiaxed.

Assuming all grains are elongated.

dCalculated average from e.

$e_{\text {Real }}$ measurements of $f$ the mean shape. 
ORIGINAT PAGE IS OF POOR QUALITY

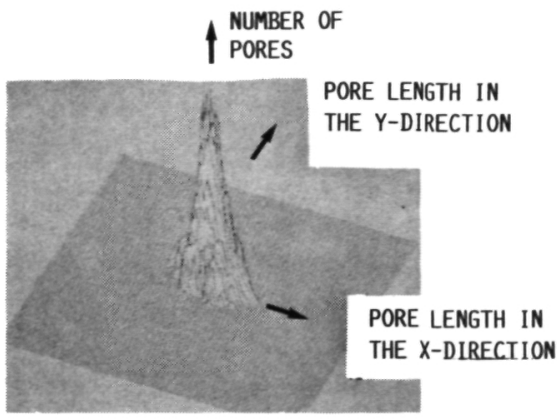

(A) PORE SIZE DISTRIBUTION.

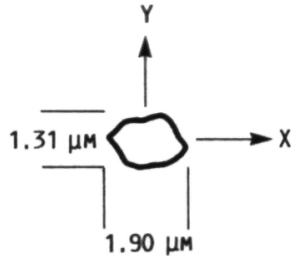

(B) MEAN PORE SIZE, SHAPE AND ORIENTATION.

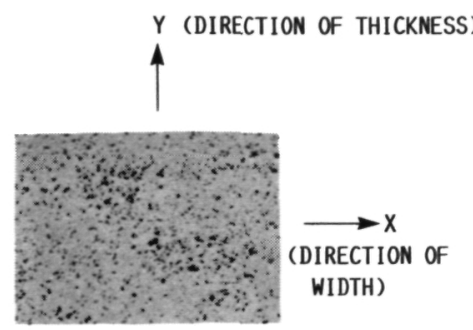

(C) PHOTOMICROGRAPH OF POLISHED MICROSTRUCTURE.

FIGURE 1. POROSITY CHARACTERIZATION OF A POLISHED SAMPLE FROM BATCH 2.

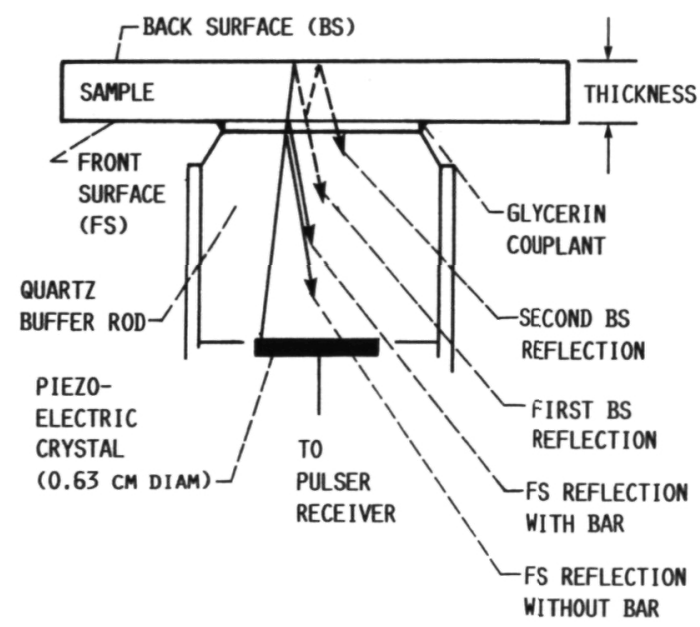

FIGURE 2. - PULSE-ECHO ULTRASONICS OF SIC BARS. 


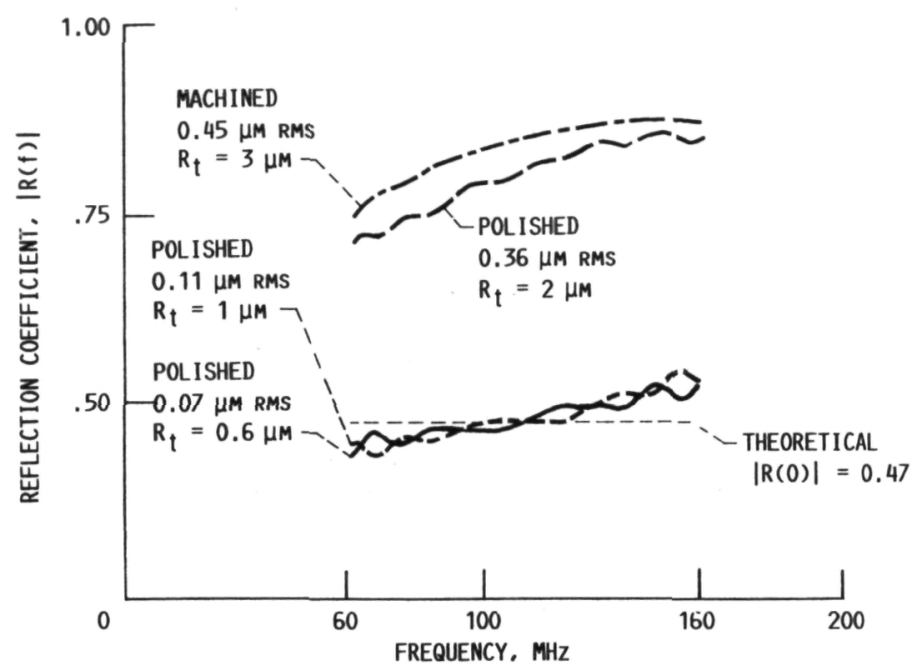

FIGURE 3. - REFLECTION COEFFICIENT FOR VARYING SURFACE ROUGHNESS OF THE SAME SAMPLE. $R_{t}$ IS MAXIMUM PEAK-TOVALLEY HEIGHT. R(0) IS THE THEORETICAL REFLECTION COEFFICIENT AT ZERO FREQUENCY.

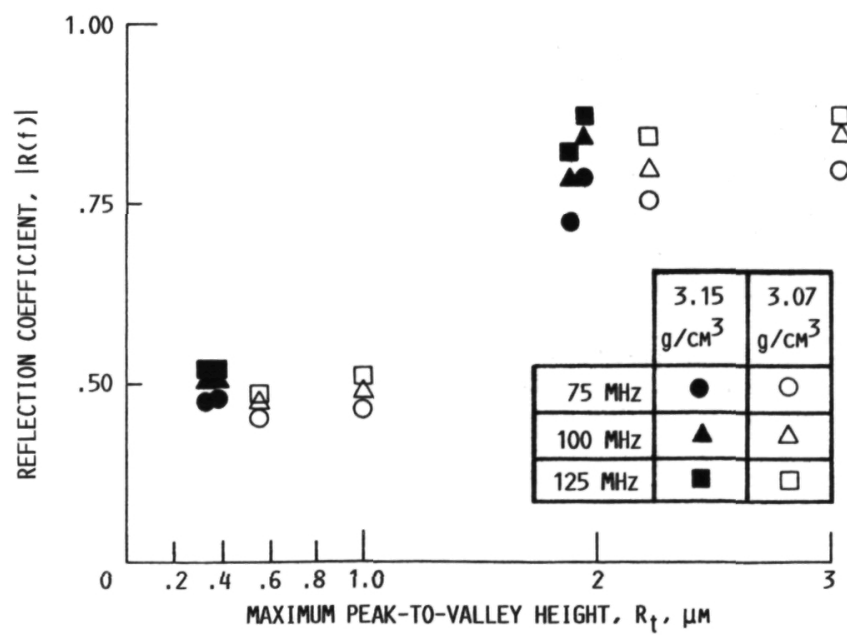

FIGURE 4. - REFLECTION COEFFICIENT VERSUS MAXIMUM PEAK-TOVALLEY HEIGHT.
몽

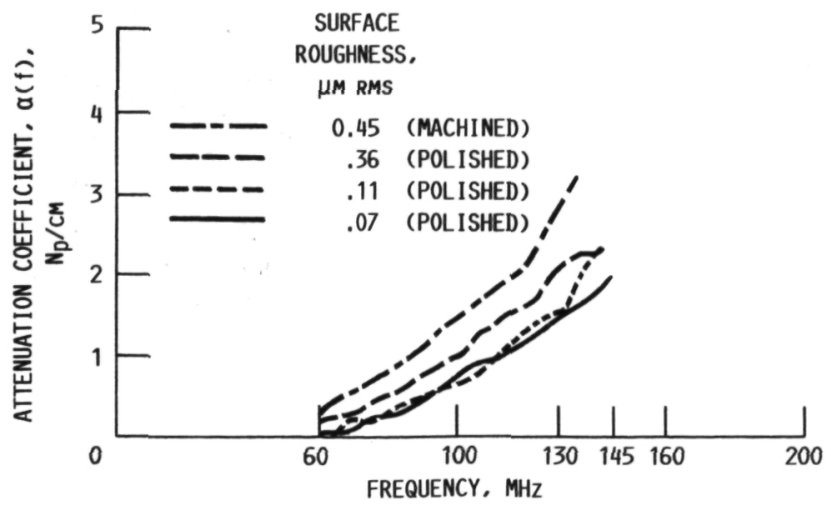

FIGURE 5.- ATTENUATION COEFFICIENT MEASUREMENTS FOR VARYING SURFACE ROUGHNESS OF THE SAME SAMPLE. 


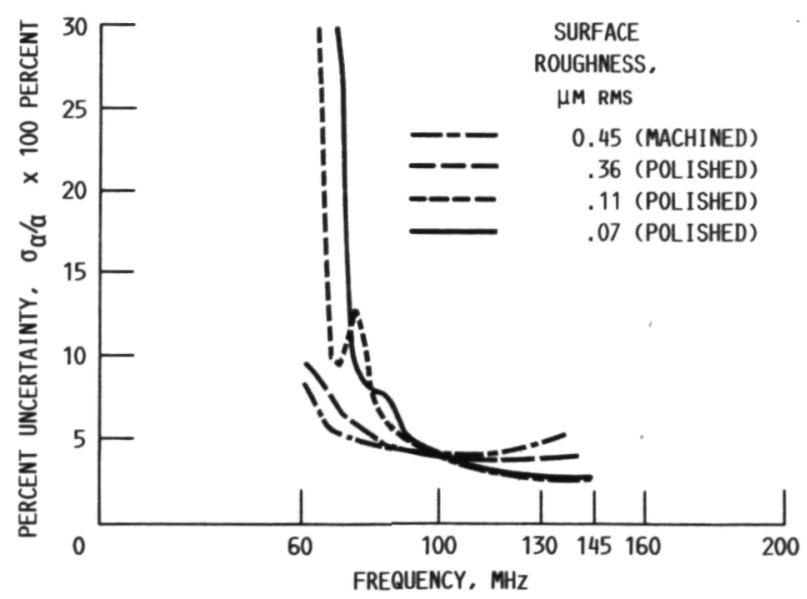

FIGURE 6. - UNCERTAINTY IN THE MEASURED ATTENUATION COEFFICIENT FOR VARYING SURFACE ROUGHNESS OF THE SAME SAMPLE.

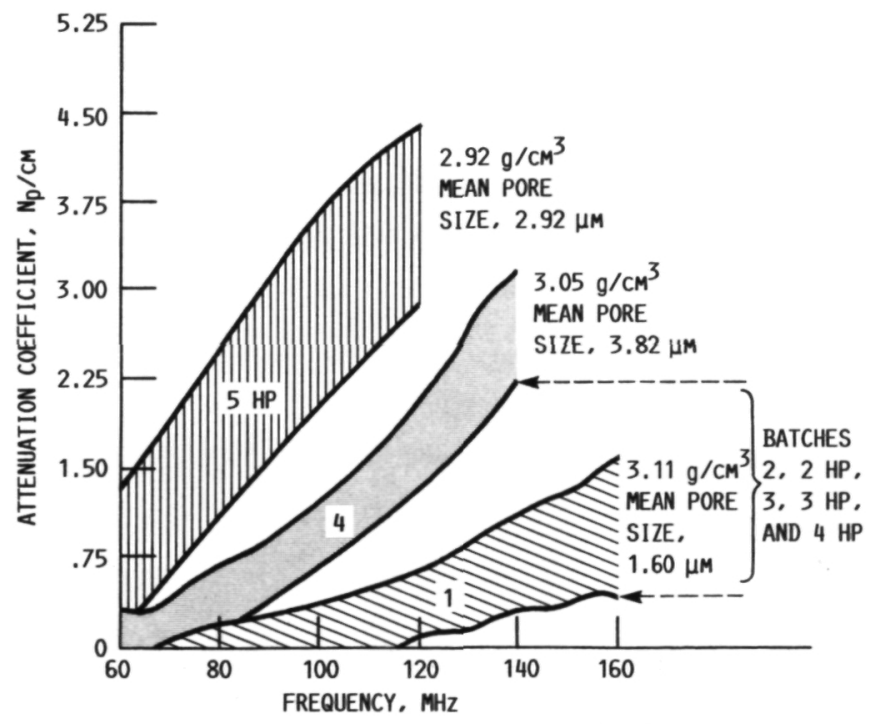

FIGURE 7. - ATTENUATION COEFFICIENT AS A FUNCTION OF FREQUENCY FOR SIC BATCHES WITH DIFFERENT DENSITIES AND MICROSTRUCTURES. 


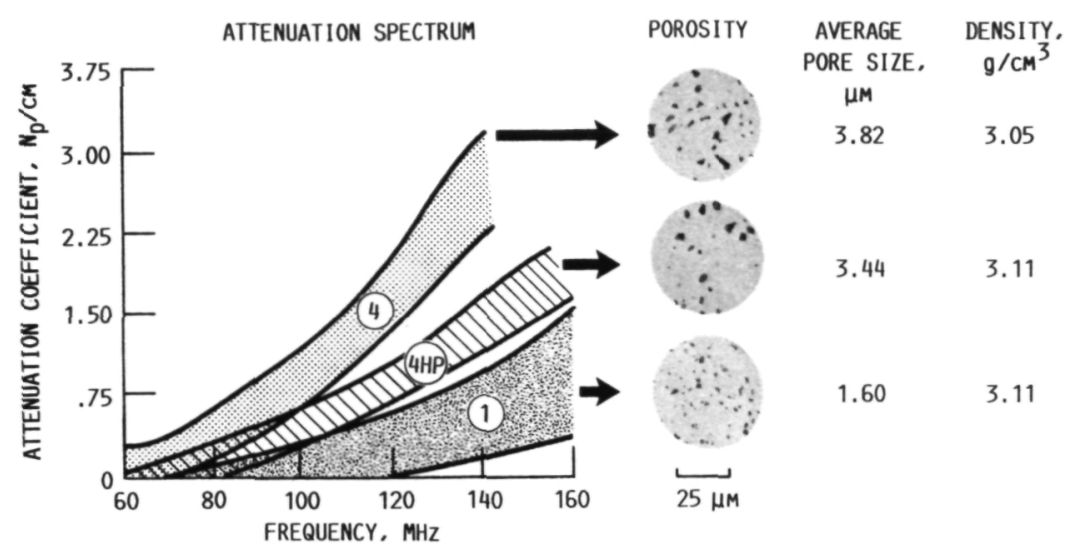

FIGURE 8. - ATTENUATION COEFFICIENT AS A FUNCTION OF FREQUENCY FOR BATCHES 1. 4. AND 4 HP.
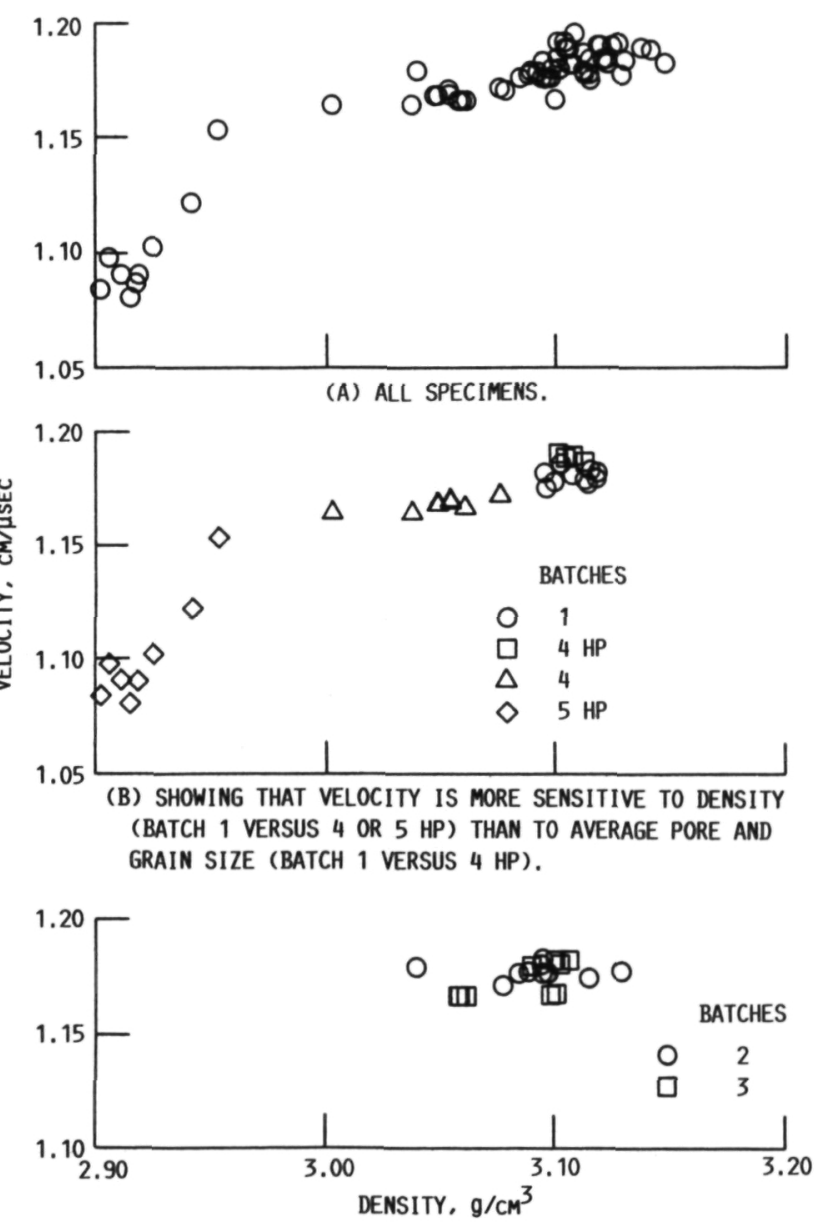

(C) DATA FROM BATCHES 2 AND 3 SHOWING THAT VELOCITY IS NOT SENSITIVE TO MEAN PORE ORIENTATION.

FIGURE 9. - ULTRASONIC VELOCITY AS A FUNCTION OF SPECIMEN BULK DENSITY. 


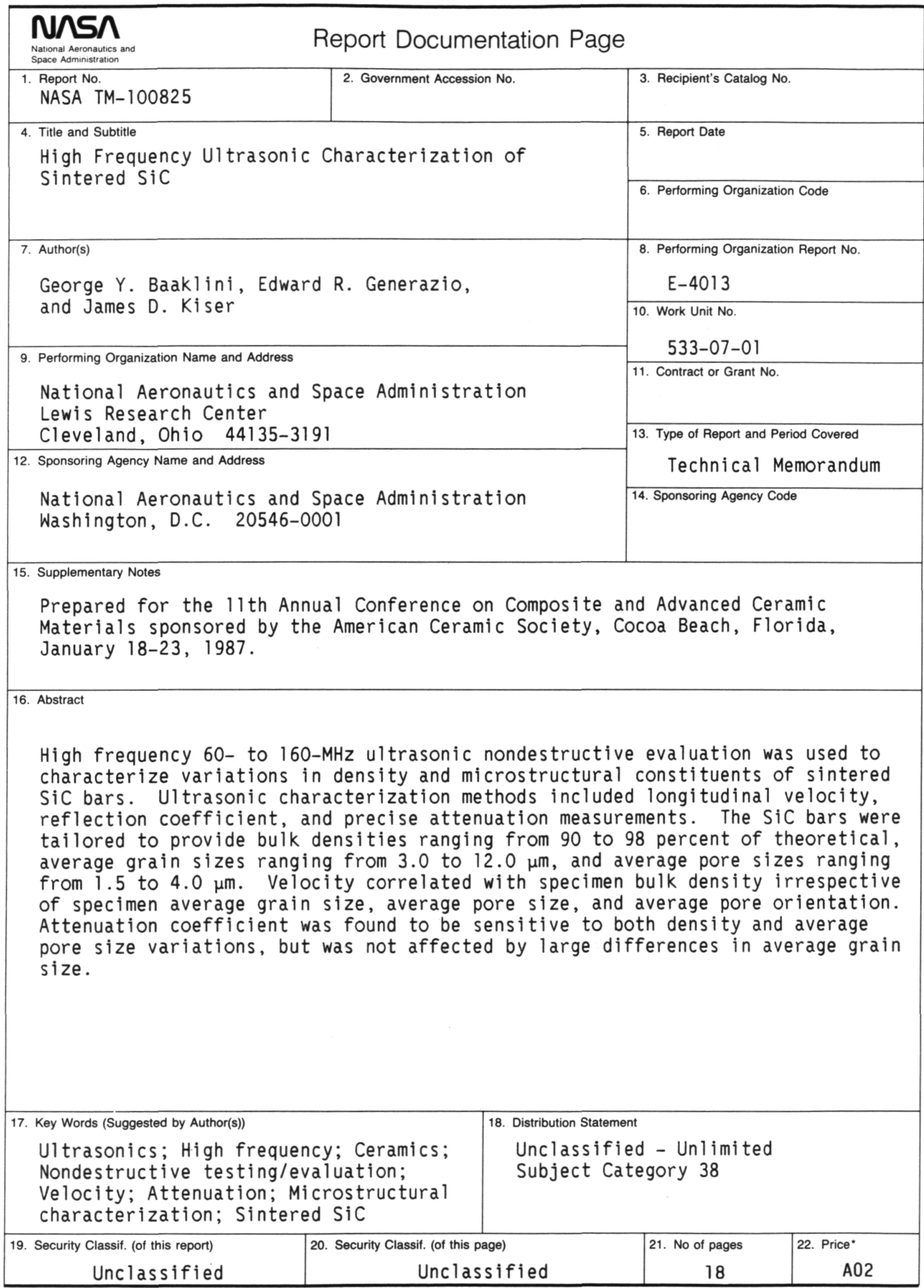


National Aeronautics and

Space Administration

Lewis Research Center

Cleveland, Ohio 44135

Official Bussiness

Penalty for Private Use $\$ 300$

\section{FOURTH CLASS MAIL}

ADDRESS CORRECTION REQUESTED

Space Administration

NASA. 451 